glycerine applied from time to time to the cervix. At the end of this period her general health had improved somewhat, but the uterine symptoms remained unchanged. Intra-uterine medication was then commenced with carbolic acid. After the third application the discharge was much diminished and the villous erosion of the cervix almost healed. After three months' treatment she was perfectly well and able for uny work. The uterus and cervix were of normal size, and the uterine leucorrhce had entirely disappeared.

CASE 2.-M. A-, aged twenty-six, a domestic servant, and unmarried, had suffered from uterine disease for four years, her prominent symptoms being constant pain and profuse discharge; and she is entirely unable to remain in service. On two separate occasions she has been an in-door patient in a metropolitan hospital for several months at a time, with only temporary relief. Uterus large, cervix greatly eroded, abundant discharge issuing from the cervix. Intra-uterine medication at once commenced. In two months she was able to take a place, but came occasionally to the hospital for treatment. This patient showed herself to me two years after she had been under my care, during which time she had been in perfect health.

CASE 3.-E. W-, aged twenty-eight. This case is of peculiar interest, inasmuch as she was sent to me in March, 1872 , as a test case, on purpose to try the effects of intrauterine medication, under the impression that her case was one which it was impossible to cure. She had been an outpatient at several hospitals and an indoor-patient in one for three months. Her case was certainly a severe test, as it was one of the worst I had ever had an opportunity of seeing. She is a single woman, but had a child some years ago, and has suffered ever since from severe abdominal pain, excessive leucorrhoal discharge, and menorrbagia. She is quite unfit for work, and her symptoms have been steadily increasing, in spite of treatment. The uterus was found to be greatly hypertrophied and tender on pressure; the cervix, large, boggy, and bleeding abundantly when touched, being covered with granular erosion. The os uteri was so patulous that it would readily admit the point of the finger, just as if it had been dilated with a sponge tent. Glairy mucus poured from it in abundance, and the penniform rugæ of whe cervical canal were so hypertrophied that they could be felt in ridges, just like the leaves of a book. The uterus was acutely retroflexed. The patient was under my care in the hospital for several months, during which time she was subjected to intra-uterine medication once a week, and iodised cotton and glycerine also applied. She improved steadily, gained flesh and strength, and the discharge greatly diminished; and then she became an out-patient. When in the hospital no attention was paid to the retroflexion, but when she went out a Hodge's pessary was applied. She was now well enough to take service, but still comes to the hospital once a fortnight. The cervix is now perfectly healthy in appearance, and the uterus of normal size. No pain is felt, and she is quite able for work. She menstruates normally. There is still rather profuse cervical discharge, but the os is now so much less patent that the probes cannot be introduced with the same ease as before, although when she came under treatment it was perfectly possible to swab out the uterine cavity with a piece of cotton held in the speculum forceps.

It is needless to multiply cases. Those I have related are sufficiently striking examples of the possibility of effecting a cure even in cases of old standing, and the im. possibility of doing it in the ordinary way, as they had each of them been subjected to the best treatment, intra-uterine medication alone excepted, that the most advanced science could afford.

$I$ append a note of one more only, from $m y$ private practice, because it forcibly illustrates the view I have taken of the secondary importance of flexion in connexion with these affections.

CASE 4. - Mrs. W- aged twenty-six, mother of three children, and has also had repeated miscarriages. Has been in India ever since her marriage. Suffered extremely from uterine symptoms, and was sent down from the provinces to be under the care of my friend, Dr. Charles, the Professor of Midwifery in Caleutta. After being there for some time she came home, bringing to me a note from Dr. Charles, stating that the nterns was in a state of subinvolution, measuring four inches and $a$ half in length, and that it was acutely retroflexed. These conditions I verified on examination. There was also very abundant uterine catarrh, great derangement of the general health, and total inability to walk on account of the pain produced. This patient was also treated with intra-uterine applications of carbolic acid, and rapidly improved; all her symptoms diminished. She lately returned to India, in perfect health, and with a uterus of normal length. Once or twice I attempted to insert a Hodge's pessary, but she never could bear it. As she improved, however, the retroflexion, which was acute and marked, entirely disappeared, and without any special attention being paid to it. I mention the case because it seems to me conclusively to prove that the flexion had not, in this case, anything to do with the causation of the disease, and that it is sometimes, under favourable circumstances, perfectly possible to cure a retroflexion without any mechanical appliances.

In conclusion, let me repeat that, while intra-uterine medication is not a panacea for all the ills that female flesh is heir to, and while I strongly deprecate its injudicious use in unsuitable cases, we have in it a most valuable means of treatment, which will serve us in good stead in some of the most troublesome and obstinate cases that come under our care, and which has by no means received the fair trial amongst us that its importance merits.

\section{ON HEREDITARY SUPRA-CONDYLOID PROCESS IN MAN.}

BY JOHN STRUTHERS, M.D., PROFESSOR OE ANATOMY IN THB UNIVERSITX OF ABBRDBHN.

I AM now able to furnish a case proving the supra-condyloid process to be hereditary. By the kindness of my esteemed pupil, Mr. Robert Milne, I was able to show to my class last winter a young man in both of whose arms the process is well developed, and the members of the class embraced the opportunity of examining the arms, and of satisfying themselves how easy it is to recognise the presence of the process in the living body. Having ascertained that the young man had relatives living in the country, I asked Mr. Milne to examine the arms carefully; and he has ascertained the following facts :-

The process is present in the left arm of the father, not so well developed as in the son above-mentioned, but distinctly felt; no trace to be felt in the right arm. There are five sons and two daughters, the daughters being third and fifth in the family. The eldest son has it very distinct in the left arm; no trace to be felt in the right. The second son has it slightly marked in the left arm; no trace in the right. The next three (the two daughters and the third son) have no trace of it perceptible in either arm. The fourth son (the one first mentioned as seen by my class) has it well developed on both sides, but most on the left. The youngest son (aged fifteen years) has it pretty well marked in the left arm; no trace felt in the right. This account of the presence of the process in this family may be relied on as regards its presence to an extent ascertainable in the living body; but from what we see in dissection, it may be present, but so short as not to admit of recognition through the sof t parts. The specimens in my collection, however, show that though well developed on one side, it is not necessarily present on the other.

Here, then, we have this remarkable variety present in the fatber in one arm, and in four of seven children; in three of the four on one side only, and that the same side as in the father (the left); while in one (the fourth son and sixth child) it has gathered force, showing itself on both sides, and more developed on either side than in the parent, the left, however, still predominating. Although the circumstances under which this variety is usually met with by the anatomist are such as almost to preclude the possibility of proving its hereditariness, there was no reason to doubt that this, like other varieties, would be transmitted by inheritance. But it is satisfactory to have the history 
of the supra-condyloid process completed by the establishment of this fact.

It would probably be found, if they were looked for, that similar cases of supra-condyloid process running in families are not very infrequent. When well, or moderately, developed, it is easily felt as a pointed projection about two inches above the internal condyle. The altered position of the median nerve and of the brachial artery (or, if double, of one of the divisions) may also be made out, though obscurely. Some of my former pupils in Edinburgh will recollect the case of the cabman whom I used to show in my lectures there, and how readily the process could be felt in both arms. I would feel obliged if any of the readers of THe LANCET who may recognise the process in a living person who has relatives within reach, will communicate with me. If anyone will take the trouble to examine the arms in any considerable hospital, or school, or regiment, he will probably find a case of it. I have met with it in various degrees of development in about one in fifty bodies, but one must not expect to be able to recognise it with certainty nearly so often in the living body.

This process would, I believe, be found to occur as a variety also among some of the higher animals in which it does not exist normally, were they examined as often and as carefully as the human body is. I noticed it on the humerus of a fossil bear in Cuvier's palæontological collection in the Jardin des Plantes, and I have the arm of a cat in which most of what should have been the bony arch is represented by ligament. Someone will probably come upon the variety in one or other of the anthropoid apes as they increase in our collections.

I do not enter here into anatomical details connected with this variety, having considered these fully in previous papers (Edinburgh Medical Journal, 1848; British and Foreign Medico-Chirurgical Review, 1854; THE LANCET, 1863); but the following illustrations may be interesting to those whose attention has not been directed to this structure.

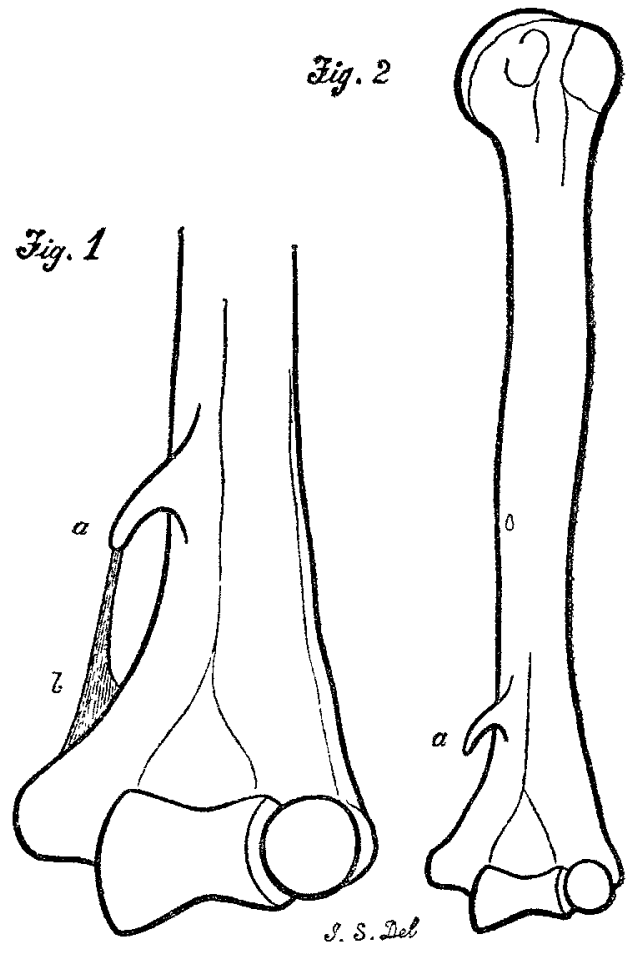

Tig. 1.-Process $(a)$ and ligament (b) completing the arch in man. Hulf natural size. The nerve, artery, and venx comites pass tbrough.

Fig. 2.-One-fourth the natural size.

In my collection may be seen a large number of specimens illustrating the various conditions of the process in man, and its relation to the soft parts.

$I$ am at present dissecting a case of cervical rib, and as this variety may be felt in the human body, I take the opportunity of saying that I would be glad if any of the readers of this paper will communicate with me if they know of a case in a person whose relatives are within reach. There is no reason why this variety should not be hereditary, and it would be interesting to have it proved. I have recognised the variety easily in the living body, and I recollect that Mr. Syme told me that he was familiar with the condition. It is liable to be mistaken for an exostosis of

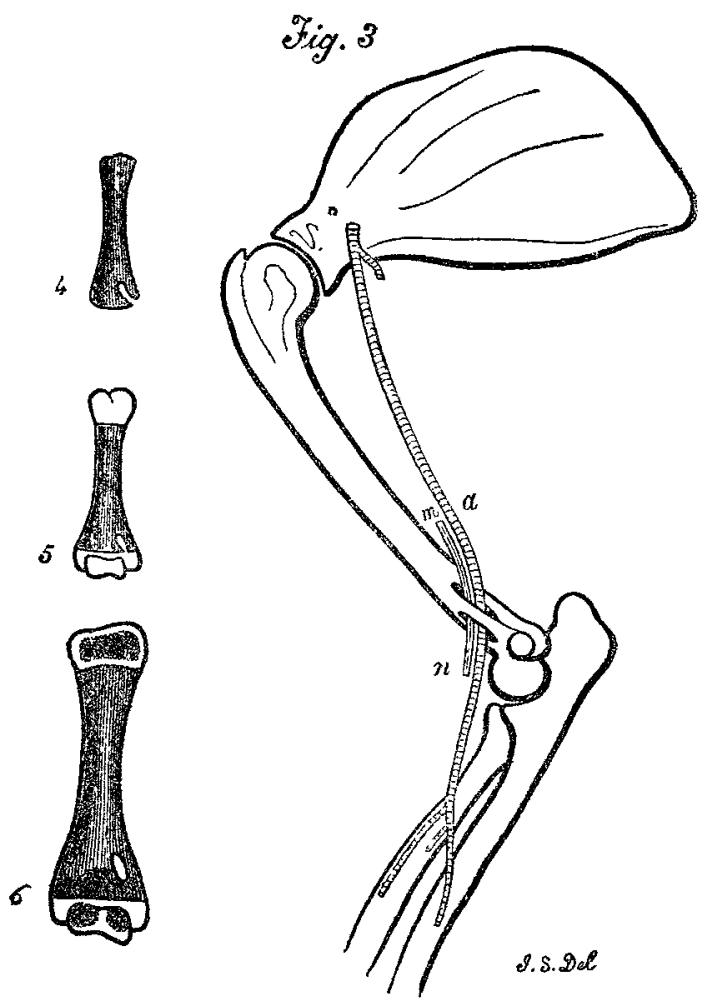

Fig. 3.-From fore-limb of cat. Half natural size. The me dian nerve $(m n)$ and brachial artery $(a)$ are seen to pass through the foramen.

Figs. 4,5, and 6 show the derelopment of the arch in the kitten: Figs. 4 and 5, at birth; Fig. 6, five weeks later. The half-grown bony arch in the kitten corresponds exactly to the full-length bony process in man.

the first rib. It may be felt as a knob-like projection in the hollow above the clavicle; the pulsation of the subclavian artery, when it is raised by the rib, being more distinct than usual.

\section{ON THE ANATOMICAL \& PHYSIOLOGICAL LOCALISATION OF MOVEMENTS IN THE BRAIN.*}

BY J. HUGHLINGS JACKSON, M.D., F.R.C.P., PHYSICIAN TO THE LONDON HOSPITAL, AND TO THR HOSPITAL TOR THE DPILEPTIC AND PARALYSED.

(Continued from p. 164)

WE have now to consider the method of representation of movements on the largest scale. Just as there are from destroying lesions of different gravities in the region of the corpus striatum ranges of paralysis from weakness of the face, arm, and leg of ane side to universal powerlessness, so from discharging lesions in this region there are all ranges of spreading of spasm from the most local to universal convulsion. Let us consider a severe convulsive paroxysm. The spasm begins, we will suppose, in the right hand, affects the right side (the face, arm, and leg), then both sides of the trunk, and next the face and limbs of the left

* My colleague, Dr. Gowers, has kindly drawn my attention to the following remarks by Sir Charles Bell :- "It is a fact familiar. to pathologists that, where debility arises from affection of the brain, the influence is greatest on those muscles which are, in their natural condition, most under the command of the will. We may perceive this in the progressive stages of de birt in the drunkard, when successively the muscles of the tongue, the eyes, the face, the limbs, become nnmanageable; and, under the same circhinces, the muscles which have a double offee-as those of the chestlose their voluntary motions and retain their involuntary motions; the "se of the arms is ,gone long before the action of breathing is affected. (Nervo point in the sides of the patient's chest move equally jn quiet breathing, whilst in 